\title{
Editorial do dossiê
}

\author{
Etienne Alfred Higuet
}

Inicio esta apresentação com uma breve descrição da Teologia da Cultura de Paul Tillich (Ver HIGUET, 2012, p. 90-93). Esta acompanhou a carreira inteira de Tillich, desde a conferência de 1919 Sobre a ideia de uma teologia da cultura, até a Teologia Sistemática (1951, 1957, 1963).

Durante os anos do primeiro ensino (1919-1926), a teologia da cultura, seguindo o programa da conferência inaugural, pretende manifestar a substância ou conteúdo religioso da cultura, isto é, o que diz respeito à questão do absoluto e dos limites da existência humana, e que transparece nas funções teóricas (artes, ciências - como a sociologia ou a psicologia profunda -, filosofia) e práticas (direito, moral, educação, política, técnica) da cultura. Esta se identifica com o mundo propriamente humano do espírito, o conjunto das atividades criadores do ser humano.

A religião, por sua vez, é "a experiência do incondicionado, isto é, a experiência da realidade absoluta na base da experiência do nada absoluto. Trata-se da experiência do nada do que existe, do nada dos valores, do nada da vida pessoal" (TILLICH, 1990, p. 35). É uma experiência nos limites da existência. "Através das coisas, esta realidade se impõe a nós, sendo, ao mesmo tempo, o não e o sim às coisas. (...) É, para usar uma fórmula mística, o além do ser. (...) Não se trata de uma realidade de ser, mas de uma realidade de sentido e, além disso, do sentido último, o mais profundo, que abala tudo e edifica tudo novamente”. “(...) A revelação do conteúdo dominante acontece à medida que a forma fica sempre mais insuficiente, que a realidade, na sua plenitude transbordante, faz estourar a forma que deveria retê-la" (TILLICH, 1990, p. 36-37). 
Em consequência, "a tarefa de uma teologia da cultura é de perseguir e expressar este processo (de rompimento da forma pelo conteúdo, sem que a forma seja perdida) em todos os setores e todas as criações da cultura. (...) Importa que todas as experiências religiosas concretas, que estão ancoradas em todas as grandes manifestações da cultura, sejam ressaltadas e levadas à expressão" (TILLICH, 1990, p. 37).

A conferência de 1919 propõe as seguintes tarefas para a teologia da cultura: uma análise religiosa geral da cultura; uma tipologia e uma filosofia histórica religiosas da cultura; uma sistematização religiosa concreta da cultura. Contudo, Tillich dedicou-se essencialmente à primeira tarefa: a análise geral de todas as criações da cultura. Trata-se de manifestar o "conteúdo substancial" (Gehalt) - ou sentido (Sinn), ou esprit (Geist), ou sagrado (Heilig) ou ainda substancialidade espiritual - que, por meio da forma, é apreendido e levado à expressão num determinado objeto (Inhalt). "É no conteúdo que a realidade religiosa aparece com o seu sim e o seu não às coisas" (TILLICH, 1990, p. 38).

$\mathrm{Na}$ Teologia Sistemática, a teologia da cultura torna-se disciplina auxiliar da sistemática: é a "tentativa de analisar a teologia subjacente a todas as expressões culturais e de descobrir a preocupação última no fundamento de uma filosofia, de um sistema político, de um estilo artístico, de um conjunto de princípios éticos e sociais. Esta tarefa é mais analítica do que sintética, mais histórica do que sistemática e constitui uma preparação para o trabalho do teólogo sistemático. No momento, uma teologia da cultura está sendo construída continuamente (...) em conexão com a história do pensamento moderno, da arte, da ciência, dos movimentos sociais (em alemão, Geistesgeschichte, 'a história do pensamento humano'). (...) Ela deveria ser ensinada como 'teologia da cultura' em todas as instituições de ensino teológico; por exemplo, como história teológica da filosofia, artes, etc.” (TILLICH, 2005, p. 55).

Na Introdução da Teologia Systemática, Tillich prossegue: "No que diz respeito ao método desta análise teológica da cultura (...) a chave para a compreensão teológica de uma criação cultural é o seu estilo. Estilo é um termo que procede do campo das artes, mas é possível aplica-lo a todos os domínios da cultura. (...) O estilo de uma época se expressa em suas formas culturais, na escolha de objetos, nas atitudes de suas personalidades criativas, em suas instituições e costumes. 'Ler 
estilos' é tanto uma arte quanto uma ciência. Requer-se uma intuição religiosa, com base em uma preocupação última, para penetrar nas profundidades de um estilo, para chegar ao nível em que uma preocupação última exerce o seu poder condutor" (TILLICH, 2005, p. 55).

Além do estilo, vários outros conceitos importantes operam na análise religiosa da cultura. Em primeiro lugar, a noção de teonomia, na sua dialética com as ideias de autonomia e heteronomia. A cultura é "teônoma" quando o sentido supremo da existência ilumina todas as formas finitas de pensamento e ação, quando a cultura se torna transparente e que suas criações se tornam receptáculos de conteúdo espiritual. Ela é "heterônoma" quando a esfera religiosa procura dominar e controlar a criatividade cultural autônoma. Enfim, a cultura é "autônoma" quando os vínculos da civilização são rompidos, junto com o seu fundamento e o seu fim últimos, num completo vazio espiritual. A partir desses conceitos, a teologia da cultura torna-se análise teônoma da cultura, capaz de mostrar a presença do fundamento teônomo incondicional e sagrado em todas as épocas e em todas as formas da cultura, até nas culturas predominantemente autônomas (ou seculares) ou heterônomas.

A ideia de teonomia deve ser completada pelas noções de kairós e de "demônico". O kairós é o tempo teônomo por excelência, é um tempo qualitativo, cheio de sentido, de tensões, de possíveis e impossíveis. Deve ser pensado como princípio geral da história, válido também para o tempo presente: os momentos de kairós são manifestações extraordinárias do eterno - aceitas, recebidas, reconhecidas - em pontos determinados da história, a qual se abre então ao incondicional. Surgindo na história, o eterno a abala e a transforma,

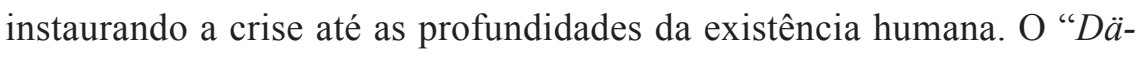
monisch" é "um princípio ambíguo, que contém um elemento criador e um elemento destruidor. É a face obscura do fundamento abissal; é o lado tenebroso do divino, assim como o experimentou Lutero. Poderíamos dizer também que é a perversão do sagrado, o sagrado com um sinal negativo". Segundo Jean-Paul Gabus, "ao contrário do satânico, que significa uma destruição completa da realidade, sem criação compensadora, o demônico exprime um aspecto essencialmente dialético, positivo e negativo, do processo vital. O demônico corresponde a uma irrupção das profundidades inesgotáveis e abissais do ser, que procura 
romper a formas finitas do ser para suscitar novas formas" (GABUS, 1969, p. 5-6). É o elemento abissal do não ser presente na criatura.

Apresentamos enfim as noções de "princípio protestante" e de Gestalt (figura, estrutura vital) de graça. O princípio protestante é um princípio universalmente significativo, que se concretizou historicamente no protestantismo, mas que atua em todos os períodos históricos, já que expressa um aspecto da relação divino-humana. Ele contém o protesto divino e humano contra toda pretensão absoluta apresentada por realidades relativas, inclusive as próprias igrejas protestantes. A Gestalt de graça é um poder de criar formas novas e superiores (artísticas, litúrgicas, comunitárias, políticas etc.) além da atitude protestante crítica em relação às formas. Embora o princípio protestante rejeite toda identificação da graça com a realidade visível, a Gestalt de graça pode, contudo, ser objeto de uma "intuição imaginativa", como no caso da figura neotestamentária de Jesus enquanto Cristo. A Gestalt de graça é transparente. Ela irradia uma realidade que é mais que ela mesma. Ela pode manifestar-se através de todas as formas seculares ou profanas, com ousadia e risco. Isso diz respeito tanto ao conhecimento quanto à ação, tanto ao culto religioso quanto à cultura autônoma.

\section{Referências}

GABUS, Jean-Paul. Introduction à la théologie de la culture de Paul Tillich. Paris: Presses Universitaires de France, 1969.

HIGUET, Etienne Alfred. Interpretação das imagens na teologia e nas ciências da religião. In NOGUEIRA, PAULO A. S. (Org.) Linguagens da religião. Desafios, métodos e conceitos centrais. São Paulo: Paulinas, 2012, p. 69-106. TILLICH, Paul. La dimension religieuse de la culture. Paris / Genève / Québec: Cerf / Labor et Fides / Laval, 1990.

TILLICH, Paul. Teologia da cultura. São Paulo: Fonte Editorial, 2009 (Tradução Jaci Maraschin).

TILLICH, Paul. Teologia Sistemática. 5. Ed. Revista, Tradução Getúlio Bertelli e Geraldo Korndörfer. São Leopoldo, RS: Sinodal, 2005. 


\section{Passamos agora à apresentação dos artigos do dossiê.}

$\mathrm{O}$ artigo de Etienne Alfred Higuet é um texto antigo, publicado pela primeira vez em 1984. Sua função aqui é de introduzir o dossiê com a apresentação das grandes linhas da Teologia da Cultura de Paul Tillich. Para o autor de Atualidade da Teologia da Cultura de Paul Tillich, a teologia de Tillich elaborou-se como um constante diálogo e confronto com os movimentos sociais, políticos, filosóficos, científicos e artísticos do século XX, no afinco de descobrir sua dimensão religiosa suprema, suas chances e seus desvios, suas exigências e seus apelos. Foi nessa intenção que Tillich construiu o "método de correlação" que o tornou famoso. É nesse sentido que toda a teologia dele pode ser qualificada de "teologia da cultura". Trata-se de explicitar, numa primeira parte, os principais conceitos que estruturam a teologia da cultura de Tillich: preocupação suprema, última ou incondicional; duplo conceito de religião; profanização e demonização; cultura e estilo; kairos e teonomia; princípio protestante. Três aplicações ilustram o projeto tillichiano de teologia da cultura: análise da cultura da sociedade industrial; análise religiosa do capitalismo e do socialismo; natureza, símbolo e sacramento.

Daniel Vieira da Silva estabelece um diálogo entre Tillich e Adorno: a cultura como um ponto de intersecção. A relação se justifica pela importância que o tema da cultura possui para os dois autores. Para Tillich, religião e cultura se complementam em uma inter-relação de substância e forma. Isso lhe permite dialogar direta e indiretamente com temas e autores não necessariamente ligados à Teologia, como Theodor Adorno, um dos líderes da Escola de Frankfurt. Trata-se, aqui, de perceber os desafios da experiência religiosa em uma sociedade de massas, administrada sob uma razão tecnológica. Além da cultura, vários outros elementos conceituais cruzam os caminhos desses autores, como, por exemplo, o interesse pelo socialismo e por Karl Marx. Além dos infortúnios históricos de uma Alemanha tomada pelo nazismo e o desafio de um exílio nos Estados Unidos, a amizade nem sempre tão presente, mas perdurada e consentida ao longo do tempo.

O símbolo Império em Paul Tillich e a ameaça autodestrutiva da sociedade angolana no romance "O cão e os caluandas" de Pepete- 
la, de Natanael Gabriel da Silva, procura problematizar a leitura que Pepetela faz sobre a sociedade angolana em "O cão e os caluandas", a partir da Teologia da Cultura e as ambiguidades da vida, tendo como referencial o símbolo Império desenvolvido por Paul Tillich. O registro do símbolo Império no referido romance de Pepetela é um caminhar pelo cotidiano de Luanda, sob o regime de um Estado controlado por um partido único. Tal situação resulta, com enrijecimento institucional por meio da burocracia monolítica em corrupção, fragmentação, desumanização e ameaça à integração, manifestado na manipulação e distorção do socialismo, identificado como "esquemático" por Pepetela. Sob a voz profética, o romancista narra a vida, as suas contradições, falta de sentido, descaminhos e sonhos recrudescidos por uma tentativa de antecipação política da vida idealizada, ou vida sem ambiguidade, antecipada e demônica, como aponta Tillich.

Para Carlos Alberto Motta Cunha, em A contribuição do pensamento de Paul Tillich para a importância da religião nas culturas urbanas da atualidade, o pensamento de Paul Tillich continua atual e desafiador. Em 2019, completa 100 anos da conferência proferida por ele na sociedade kantiana de Berlim, 16 de abril de 1919, intitulada "Sobre a ideia de uma teologia da cultura". A explanação de Tillich é tida como o marco inicial da sua Teologia da Cultura e fonte de inspiração para pensar a correlação entre religião e cultura. Em comemoração a esse referencial, a reflexão aqui proposta busca fazer alguns apontamentos introdutórios sobre a contribuição do pensamento tillichiano para a importância da religião nas culturas urbanas da atualidade. Para isto, o texto está dividido em dois momentos. Primeiro, uma breve análise da crise da religião, do sujeito religioso e da devoção ao mercado financeiro, segundo, a teologia da cultura de Tillich empenhada em ressignificar os símbolos da fé e correlacionar religião e cultura como caminho de busca de sentido para o ser humano de hoje.

$\mathrm{O}$ artigo de Pablo Fernando Dumer: Doente de Brasil: uma análise tillichiana da situação atual no Brasil, se propõe a analisar a situação atual do Brasil inserindo-se no processo vivo de reflexão, questionamento e reação às consequências sociais e antropológicas do momento político e econômico contemporâneos. Para isso, parte inicialmente da reflexão da escritora Eliane Brum acerca da corrosão das relações 
desde o conceito de autoverdade e dialoga com a teologia da cultura de Paul Tillich, seu contexto e as chaves teológicas, buscando inspiração e energia para o papel da teologia e da religiosidade no processo de articulação de resposta, reafirmação e resistência à diluição da verdade.

Elton Vinicius Sadao Tada e Veronica Regina Müller apresentam o texto Educação para a infância na América Latina: uma perspectiva a partir da Teologia da Cultura. O artigo discute a educação para a infância na América Latina a partir da Teologia da cultura de Paul Tillich. Para isso, o texto é dividido em três partes. Primeiramente uma apresentação da educação da infância na América Latina, em seguida faz-se uma aproximação fenomenológica a essa questão a partir do pensamento tillichiano e, por último apresenta-se uma proposição para a educação da criança na América Latina a partir de princípios tillichianos.

Enfim, o ensaio de Victor Siqueira Campos: Sobre a ideia de uma Teologia da Cultura de Consumo: ensaio de um olhar tillichiano sobre a cultura de consumo, visa apontar um caminho para a construção de uma teologia da cultura de consumo a partir da teologia da cultura de Paul Tillich. Para tal, o primeiro objetivo será entender, pelo viés antropológico, o que é e quais são as principais características da chamada cultura de consumo. Após, então, é pretendido mostrar que a teologia da cultura de Paul Tillich visa superar a separação entre cultura e religião, defendendo que toda e qualquer criação cultural é capaz de trazer consigo um conteúdo religioso. Portanto, é tarefa da teologia da cultura analisar tais manifestações culturais sempre do ponto de vista de seu conteúdo substancial (Gehalt). Como delimitação necessária, será considerado como fundamento teórico o texto Über die Idee einer Theologie der Kultur (Sobre a ideia de uma teologia da cultura), proferido por Tillich em 16 de abril de 1919 à Sociedade Kantiana de Berlim, visto que esta conferência é a primeira aparição pública de sua teologia da cultura. A hipótese consiste, por fim, em mostrar que, a partir da teologia tillichiana, é possível afirmar a cultura de consumo como uma esfera cultural que absolutiza o caráter autônomo da cultura, travestindo-a de teonomia. 